\title{
How Mothers Cook in Chile: an Experimental Exercise to Use Food Labels to Control Portion Sizes
}

\author{
Dario Gregori ${ }^{1, *}$, Simonetta Ballali ${ }^{2}$, Maria Gabriella Vecchio ${ }^{2}$, Luis Marcel Valenzuela Contreras ${ }^{3}$, \\ Jorge Baeza Correa ${ }^{3}$, Cecilia Bahamonde Perez ${ }^{4}$, Jorge Barrera Luengo ${ }^{5}$, Edgardo Moyano 5 , \\ Maurizio Arrieta ${ }^{6}$ and Angelo Gutierrez ${ }^{6}$
}

\author{
${ }^{1}$ Unit of Biostatistics, Public Health and Epidemiology, Dept. Cardiology, Thoracic and Vascular Sciences, University \\ of Padova, Italy \\ ${ }^{2}$ Prochild Onlus, Trieste, Italy \\ ${ }^{3}$ Universidad Católica Silva Henríquez, Santiago de Chile, Chile, Italy \\ ${ }^{4}$ Facultad de Ciencias Médicas, Universidad de Santiago de Chile, Chile, Italy \\ ${ }^{5}$ Colegio Santo Domingo Savio, Santiago de Chile, Chile, Italy \\ ${ }^{6}$ Colegio Camilo Ortuzar Montt, Santiago de Chile, Chile, Italy
}

\begin{abstract}
Portion size of food and drink products is an important factor when providing nutrition information for food labeling purposes. The present study was conducted in order to understand more about consumer attitudes and understanding of portion size information on food and drink products. An experimental trial was performed on mothers and one of their relative. The participants were asked to prepare two meals (one meant for a child, one for an adult), with ingredients measured only with kitchen tools. Participants were stratified by portion size information in two groups, one with labels bearing the "100 gram" and one with "per portion". Subsequently, every participant was interviewed on the basis of a questionnaire assessing nutritional and portioning knowledge. When measured the total Kcal of prepared meals after the simulation, an increase of calories was recorded in the group of subjects who prepared foods bearing the $100 \mathrm{~g}$ label, although not statistically significant $(\mathrm{p}=0.842)$. Portion size use seemed to be a more intuitive way to properly share nutritional information on food label, especially when considering common traditional recipes. Meals responsible appeared to be much more at ease with per portion labeling, when preparing both children's meals and adult ones.
\end{abstract}

Keywords: Chile, food label, meal preparation, nutritional information, per $100 \mathrm{~g}$, per portion.

\section{INTRODUCTION}

The prevalence of overweight and obese people is drastically increasing worldwide [1].In this background, careful control of food intake is needed in several conditions such as disease management or research on nutrients' effect on health [2]. Labeling information on nutrients' content has received considerable attention in recent years [3]. The potential of labeling can be considered on the basis of different perspectives: as a marketing tool, as a relevant mean of communication used from an industry viewpoint and as information bearer channel for consumers [4]. Nutrition labeling, if applied correctly and if adequately used and understood by the consumer, can be an easy and direct tool in order to help users in taking into account the nutritional content of the food product in their purchase decisions [5].

*Address correspondence to this author at the Unit of Biostatistics, Public Health and Epidemiology, Dept. Cardiology, Thoracic and Vascular Sciences, University of Padova University of Padova, Via Loredan, 18, 35121 Padova - Italy; Tel: +39049 8275384; Fax: +39 02700445089 ;

E-mail: dario.gregori@unipd.it
Several countries subscribed written rules in order to regulate the information contained in food labels. Nutrition facts labeling is mandatory in Chile, where legislative regulations on nutrition labels have been mostly based on the Codex Alimentarius [6]. Since 1997, Chile has had a national Codex commission, representing Chile at Codex meetings. Together with the US Nutritional Labeling and Education Act (NLEA), which went into effect in 1994 and required that most food products carried a nutrition facts' panel, these have been landmarks in nutrition labeling policy [7].

However, the actual impact of labels on nutrition behavior seems to be less effective than expected [8], as the North American example might well represent, where obesity among the general population is still increasing, although the country has been exposed to nutrition labeling of foods for almost two decades,.

In order to better assess factors biasing the expected results of such policies, it is necessary to highlight here that there is little prior research to guide key decisions on whether caloric content should be expressed in absolute terms or relative, whether it should be expressed in per 
Table 1. Ingredients of Study Receipts

\begin{tabular}{|c|c|c|c|c|c|}
\hline Ingredient & Product Name & Weight & Portion & $\begin{array}{c}\text { Kcal } \\
\text { Per Portion }\end{array}$ & Kcal Per $100 \mathrm{~g}$ \\
\hline Pasta & Espirales Precio Uno & $400 \mathrm{~g}$ & $80 \mathrm{~g}$ & 293 & 354 \\
\hline Oil & Aceite $100 \%$ Maravilla & $1 \mathrm{lt}$ & 7 ml-1 spoon & 58 & 828 \\
\hline Salt & Sale fino & $1 \mathrm{~kg}$ & 1g-1/4 spoon & 0 & 0 \\
\hline Tomato sauce & Pomarola de Carozzi & $200 \mathrm{~g}$ & $20 \mathrm{~g}$ & 9 & 46 \\
\hline Cheese & Regianito de Colun & $40 \mathrm{~g}$ & $10 \mathrm{~g}-2$ spoons & 47 & 469 \\
\hline Mashed potatoes & Puré de Papas Bonanza & $250 \mathrm{~g}$ & 31 g-2 spoons & 116 & 370 \\
\hline Flour & Harina Mont Blanc & $3 \mathrm{~kg}$ & 50g-half cup & 171 & 342 \\
\hline
\end{tabular}

serving or per $100 \mathrm{~g}$ [9]. An additional subject at the centre of interest is whether the information should be presented to the consumers and also the way in which it should be written and placed on the label [9]. In fact, if applied correctly and if adequately used, nutritional label may be a valid tool in decision making and consequently in taking informed choices for healthy options and hence for a more healthy diet [10-12].

Although it is evident that nutrition labeling communicates important information to consumers, there are no scientific data that convincingly show that nutrition labeling improves dietary patterns. Such evidence is largely confined to self-reported measures often collected under controlled situations, which casts doubt on their generalization to real-life food choice conditions [13].

Several consumer studies on the most frequently lookedat information on food labels in Europe revealed that calories were always among those on top of the list [14].

As reported in Ledikwe's study [15], portion sizes seem to be a valid starting point for the development of various environmental interventions directed at the prevention and treatment of obesity.

Our study aimed at assessing Chilean consumers' understanding and interest in nutrition information on food labels, practically assessing their daily use in meal preparation. Chilean consumers were therefore assessed not only on their preferences, but were also tested on label use, with specific attention to total calories of prepared meals when using products bearing a "100gr" or "per portion" label.

\section{MATERIALS AND METHODS}

The study was developed into two main phases. The first phase was an experimental trial in which participants had to prepare two typical Chilean's meals, while the second one consisted in a one-to-one interview performed by trained interviewer on a Chilean sample of consumers.

The sample was randomized in two groups; half participants receiving ingredients labeled with nutrition information/100 gram, the other half with information/per portion data. Participants were the mothers and a close relative of the kids involved in the OBEY-AD study, performed by the authors on a sample of Chilean children.
Labels content was investigated in two phases, aimed at understanding the routinely behaviors of family meals' responsible in choosing and proper use of ingredients, and the knowledge and the habits of the participants with respect to specific labels and nutritional information.

Before the first phase, no indication on the content of the experimental session was given to the participants, in order to avoid any possible influence.

In the first stage, participants were asked to prepare two repasts. Groups were provided of meals' recipes and all the necessary ingredients and were asked to simulate the preparation of two main meals, the first one meant for a child, the second for an adult (respectively, Chapalele: flour, boiled potatoes, salt, oil, and Talarrinescon salsa de tomate: pasta, tomato sauce, cheese, salt, oil). Ingredients and nutritional contents of the receipts are listed in Table $\mathbf{1}$.

Participants were instructed by the operator to prepare the dishes, and all movements and decisions were recorded from a high definition camera, set aside by the table in order to catch the portioning act. Participants were made aware that the dishes that they were invited to prepare were part of a meal and not the single course of it. Kcalories (Kcal) per dish were therefore set at $200 \mathrm{Kcal}$.

In the second phase, a questionnaire developed by the authors was administered in order to evaluate knowledge on nutrition and healthy lifestyle, use and comprehension of labels and correct interpretation of given portions.

The questionnaire was organized in 5 different parts, each one containing specific information. Section A aimed at collecting basic information on the participants, linking them to the child and child's questionnaire filled during the participation to the OBEY-AD study. Section B was developed in order to frame nutritional beliefs and behavioral aspects linked to lifestyle. Section $\mathrm{C}$ guided the respondents to deepen the concepts of portion size, catching the decision making process when considering nutritional labels, evaluating consumers' preferences with respect to nutritional information presentation, assessing pertinence and accuracy of labeling knowledge, and the interest in gathering information during the purchasing process.

Section D tested specific understanding and use of portion size information in meal decisions. At the end, 
Table 2. First Three Elements Recalled from Respondents when Inquired on Labels, Given as Relative Frequencies. Absolute Frequencies are Reported in Brackets

\begin{tabular}{|c|c|c|c|c|c|}
\hline Labeling Recall & $\mathbf{N}$ & Per 100gr Group & Per Portion Group & Overall & Test Statistic \\
\hline Expiry date & 114 & $80(45)$ & $88(51)$ & $84(96)$ & $\mathrm{p}=0.268$ \\
\hline Nutrition information & 114 & $43(24)$ & $40(23)$ & $41(47)$ & $\mathrm{p}=0.728$ \\
\hline Fat & 114 & $30(17)$ & $38(22)$ & $34(39)$ & $\mathrm{p}=0.394$ \\
\hline Sodium & 114 & $34(19)$ & $26(15)$ & $30(34)$ & $\mathrm{p}=0.347$ \\
\hline Sugar & 114 & $27(15)$ & $26(15)$ & $26(30)$ & $\mathrm{p}=0.911$ \\
\hline Calories & 114 & $23(13)$ & $21(12)$ & $22(25)$ & $\mathrm{p}=0.745$ \\
\hline Cholesterol & 114 & $11(6)$ & $10(6)$ & $11(12)$ & $\mathrm{p}=0.949$ \\
\hline Calcium & 114 & $4(2)$ & $16(9)$ & $10(11)$ & $\mathrm{p}=0.031^{*}$ \\
\hline Production site & 114 & $9(5)$ & $9(5)$ & $9(10)$ & $\mathrm{p}=0.954$ \\
\hline Package's weight & 114 & $7(4)$ & $9(5)$ & $8(9)$ & $\mathrm{p}=0.77$ \\
\hline Carbohydrates & 114 & $7(4)$ & $7(4)$ & $7(8)$ & $\mathrm{p}=0.959$ \\
\hline Portion's weight & 114 & $9(5)$ & $2(1)$ & $5(6)$ & $\mathrm{p}=0.085$ \\
\hline Proteins & 114 & $4(2)$ & $3(2)$ & $4(4)$ & $\mathrm{p}=0.972$ \\
\hline No answer & 114 & $0(0)$ & $5(3)$ & $3(3)$ & $\mathrm{p}=0.085$ \\
\hline Iron & 114 & $0(0)$ & $2(1)$ & $1(1)$ & $\mathrm{p}=0.324$ \\
\hline
\end{tabular}

*p value significant $(\mathrm{p}<0.05)$

section E tested, through a visual tool, knowledge on proper portioning for a healthy food consumption during all meals (breakfast, morning snack, lunch, afternoon snack, alcohol consumption). Participants could choose between three images showing the correct portion of meal, a reduced one and an excessive one. For midmorning and afternoon snacks, possibilities ranged from the correct portion to two increased one.

\section{RESULTS}

114 subjects were equally divided in 2 settings. $86 \%$ of the participants were of Chilean nationality, $60 \%$ of white ethnic group, while 26\% were Mestizo. The majority (48\%) belonged to the $35-44$ age group and the $68 \%$ of participants belonged to a low SEC. From a general overview of the questionnaire, 98\% considered obesity as a current severe problem. Overweight and obesity were a personal issue in $53 \%$ of the interviewees and the $80 \%$ declared that their partner or their children had the same problem. As general rule, $25 \%$ of the respondents said that when eating more, they were performing more physical activity in accordance, while the $49 \%$ declared to habitually maintain regular patterns of diet and physical activity. Considering the total sample, $44 \%$ declared to generally eat healthy and do exercise. More specifically, $61 \%$ affirmed to be physically active, while the $30 \%$ acknowledged performing habitually aerobic activities.

Participants were therefore assessed on their habits regarding labeling and label preferences. In $84 \%$ of cases, the first element considered when reading food label was the expiry date, while the $40 \%$ considered nutritional information. $25 \%, 32 \%$ and $30 \%$ of the respondents were respectively interested in assessing sugar, fats and cholesterol. All data are presented in Table 2.

Interviewees stated to regularly read labels in $38 \%$ of cases, but there was a significant difference on frequency of reading when considering the two groups $(p<0.05)$. When asked whether they were usually assessing caloric intake of their meals, 39\% answered they never were. They showed anyway a correct knowledge on the definition of size of portion $(39 \%)$, while definitions of serving methods were incorrect in the $68 \%$ and $59 \%$ of cases when considering per $100 \mathrm{gr}$ and per portion respectively. In the latter question, a significant difference was found when confronting per 100 gr and per portion groups $(\mathrm{p}<0.05)$.

Several questions were subsequently presented in order to mimic real purchasing situations. All answers and frequencies are presented in Table 3. Participants preferred Kcal per portion as serving size method in $61 \%$ of cases, showing no significant difference among the two groups of evaluations. Similar results were found when considering front-of-pack (FOP) label, showing that the majority of respondents choose nutrition facts expressed as gr per portion among the different options. There was an overall low trust on portion facts' given from food industry by mean of labels, and consumers resulted less convinced when considering information on fruits and vegetables $(20 \%)$ and condiments (7\%). In addition, end users declared to need advices on portion size and calories when consuming fruits and vegetables in the $80 \%$ of cases. However, less than half of the respondents stated to observe portion size nutritional 
Table 3. Labelling knowledge,Preferences and Trust. When given more Options, Results are Presented Only for the First Choice. All Data are given as Relative Frequencies. Absolute Frequencies are Reported in Brackets

\begin{tabular}{|c|c|c|c|c|c|}
\hline & $\mathbf{N}$ & $\begin{array}{l}\text { Per 100gr } \\
\text { Group }\end{array}$ & $\begin{array}{l}\text { Per Portion } \\
\text { Group }\end{array}$ & Overall & Test Statistic \\
\hline \multicolumn{6}{|c|}{ Understanding. Are nutrition facts more comprehensible when they refer to $100 \mathrm{gr}, 100 \mathrm{Kcal}$ or a portion of the product? } \\
\hline Per portion & & $41(23)$ & $57(33)$ & $49(56)$ & $\mathrm{p}=0.106$ \\
\hline Per $100 \mathrm{gr}$ & & $36(20)$ & $33(19)$ & $34(39)$ & \\
\hline Per $100 \mathrm{Kcal}$ & & $21(12)$ & $7(4)$ & $14(16)$ & \\
\hline No answer & 114 & $2(1)$ & $3(2)$ & $3(3)$ & \\
\hline \multicolumn{6}{|c|}{ Preference on serving size. How would you prefer Kcal to be expressed on front of pack nutrition facts? } \\
\hline Kcal per $100 \mathrm{gr}$ & 114 & $7(4)$ & $10(6)$ & $9(10)$ & $\mathrm{p}=0.493$ \\
\hline gr per $100 \mathrm{Kcal}$ & 114 & $36(20)$ & $24(14)$ & $30(34)$ & $\mathrm{p}=0.274$ \\
\hline Kcal per portion & 114 & $57(32)$ & $66(38)$ & $61(70)$ & $\mathrm{p}=0.655$ \\
\hline \multicolumn{6}{|c|}{ Preference on Front-of- Pack symbols. Which FOP symbol would you prefer the most? } \\
\hline $\begin{array}{l}\text { Nutrition facts pile, stating sugars, saturated fats } \\
\text { and salt in grper portion }\end{array}$ & 114 & $23(13)$ & $28(16)$ & $25(29)$ & $\mathrm{p}=0.215$ \\
\hline Traffic light & 114 & $29(16)$ & $22(13)$ & $25(29)$ & $\mathrm{p}=0.551$ \\
\hline Health symbols (green brand, etc) & 114 & $18(10)$ & $29(17)$ & $24(27)$ & $\mathrm{p}=0.241$ \\
\hline Total Kcal, with \& of sugar, fat and salt & 114 & $20(11)$ & $16(9)$ & $18(20)$ & $\mathrm{p}=0.931$ \\
\hline Total Kcal (with respect to GDA) & 114 & $11(6)$ & $5(3)$ & $8(9)$ & $\mathrm{p}=0.046$ \\
\hline \multicolumn{6}{|c|}{$\begin{array}{c}\text { Consumers trust. Do you think that food industry proposes correct description of food portions on these products? (The "yes" modalities have been } \\
\text { reported. }\end{array}$} \\
\hline Soft Drinks & 114 & $36(20)$ & $50(29)$ & $43(49)$ & $\mathrm{p}=0.123$ \\
\hline Canned food & 114 & $27(15)$ & $47(27)$ & $37(42)$ & $\mathrm{p}=0.029$ \\
\hline Meat, fish and eggs & 114 & $29(16)$ & $28(16)$ & $28(32)$ & $\mathrm{p}=0.907$ \\
\hline Dried legumes & 114 & $18(10)$ & $33(19)$ & $25(29)$ & $\mathrm{p}=0.068$ \\
\hline Snack & 114 & $23(13)$ & $28(16)$ & $25(29)$ & $\mathrm{p}=0.592$ \\
\hline Fruits and vegetables & 114 & $20(11)$ & $21(12)$ & $20(23)$ & $\mathrm{p}=0.889$ \\
\hline Condiments & 114 & $4(2)$ & $10(6)$ & $7(8)$ & $\mathrm{p}=0.157$ \\
\hline
\end{tabular}

Table 4. Results of Visual Test on Portion Knowledge. All Results are Given as Relative Frequencies. Absolute Frequencies are Reported in Brackets

\begin{tabular}{|c|c|c|c|c|c|}
\hline & $\mathbf{N}$ & Per 100gr Group & Per Portion Group & Overall & Test Statistic \\
\hline \multicolumn{6}{|c|}{ Breakfast } \\
\hline Reduced & 114 & $18(10)$ & $14(8)$ & $16(18)$ & $\mathrm{p}=0.759$ \\
\hline Correct & & $36(20)$ & $41(24)$ & $39(44)$ & \\
\hline Excessive & & $46(26)$ & $45(26)$ & $46(52)$ & \\
\hline \multicolumn{6}{|c|}{ Midmorning Snack } \\
\hline Correct & 114 & $95(53)$ & $86(50)$ & $90(103)$ & $\mathrm{p}=0.169$ \\
\hline Excessive & & $5(3)$ & $9(5)$ & $7(8)$ & \\
\hline Extremely excessive & & $0(0)$ & $5(3)$ & $3(3)$ & \\
\hline
\end{tabular}


Table 4. contd...

\begin{tabular}{|c|c|c|c|c|c|}
\hline & $\mathbf{N}$ & Per 100gr Group & Per Portion Group & Overall & Test Statistic \\
\hline \multicolumn{6}{|c|}{ Lunch } \\
\hline Correct & & $59(33)$ & $62(36)$ & $61(69)$ & \\
\hline Excessive & & $34(19)$ & $28(16)$ & $31(35)$ & \\
\hline Reduced & 114 & $48(27)$ & $34(20)$ & $41(47)$ & $\mathrm{p}=0.18$ \\
\hline Correct & & $43(24)$ & $47(27)$ & $45(51)$ & \\
\hline Excessive & & $9(5)$ & $19(11)$ & $14(16)$ & \\
\hline \multicolumn{6}{|c|}{ Afternoon Snack } \\
\hline Extremely excessive & & $7(4)$ & $7(4)$ & $7(8)$ & \\
\hline \multicolumn{6}{|c|}{$\begin{array}{c}\text { Dinner } \\
\text { Side Dish }\end{array}$} \\
\hline Reduced & 114 & $57(32)$ & $55(32)$ & $56(64)$ & $\mathrm{p}=0.291$ \\
\hline Correct & & $38(21)$ & $31(18)$ & $34(39)$ & \\
\hline Excessive & & $5(3)$ & $14(8)$ & $10(11)$ & \\
\hline \multicolumn{6}{|c|}{ Rice } \\
\hline Correct & & $43(24)$ & $43(25)$ & $43(49)$ & \\
\hline Excessive & & $5(3)$ & $3(2)$ & $4(5)$ & \\
\hline
\end{tabular}

facts when buying or before consuming the product (respectively $43 \%$ and $42 \%$ ).

The last session of the questionnaire assessed participants' knowledge and use of serving size through a visual tool. Respondents showed an overall paucity of knowledge. All results are presented in Table 4.

When considering the practical session, total Kcalories of prepared meals were evaluated after the simulation. In Fig. (1), results coming from the whole sample are presented. An increase of calories was recorded in the group of subjects who prepared foods bearing the $100 \mathrm{~g}$ label, although not statistically significant $(\mathrm{p}=0.842)$. In the $100 \mathrm{gr}$ group, outliers with unusually high (or low) observed values were documented.

Fig. (2) presents data on the sub sample that stated to not usually read nutrition information. A statistically significant difference was registered when evaluating both preparation $(\mathrm{p}=0.039)$.

\section{DISCUSSION}

In light of the emerging obesity pandemic, the scheme of nutritional composition onto FOP labels may be an important tool to assist consumers in making informed healthier food choices [9], because it would reduce what Verbeke called "information asymmetry" [16] that is the gap of knowledge on purchased product existing between consumers and the industry. [16].

Nutrition labeling on food products has emerged as a prominent policy tool for promoting healthy eating [13]. As a health education intervention, mandatory nutrition labels have broad reach and are present at the point of purchase, as well as when food is prepared or consumed [17]. The display of nutritional information on pre-packaged foods is mandatory in most high-income countries and in developing 


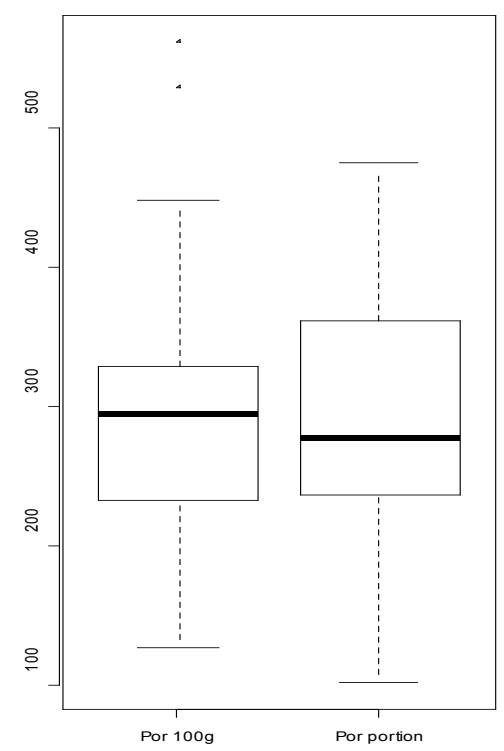

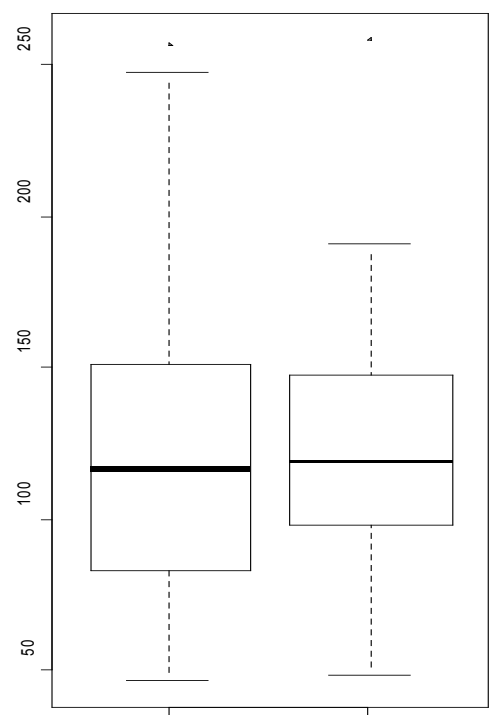

Por $100 \mathrm{~g}$

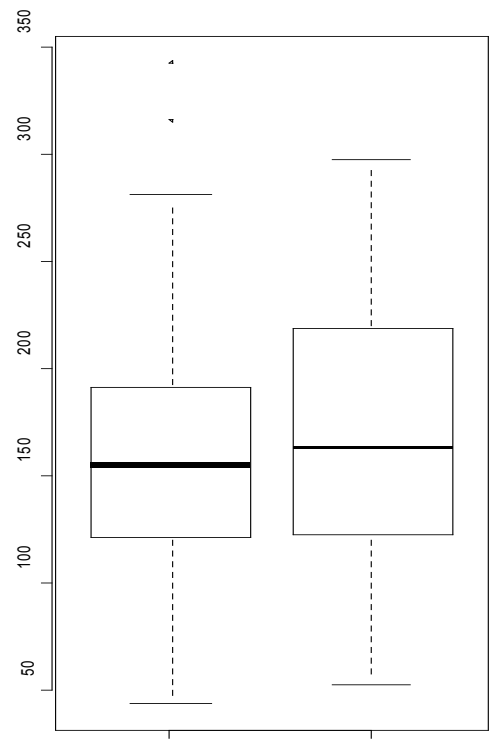

Por $100 \mathrm{~g}$

Por portion

Fig. (1), Kcal of experimental meals. The first box-plot is referred to both meals. The second and the third are respectively referred to kids' and adults' meal.
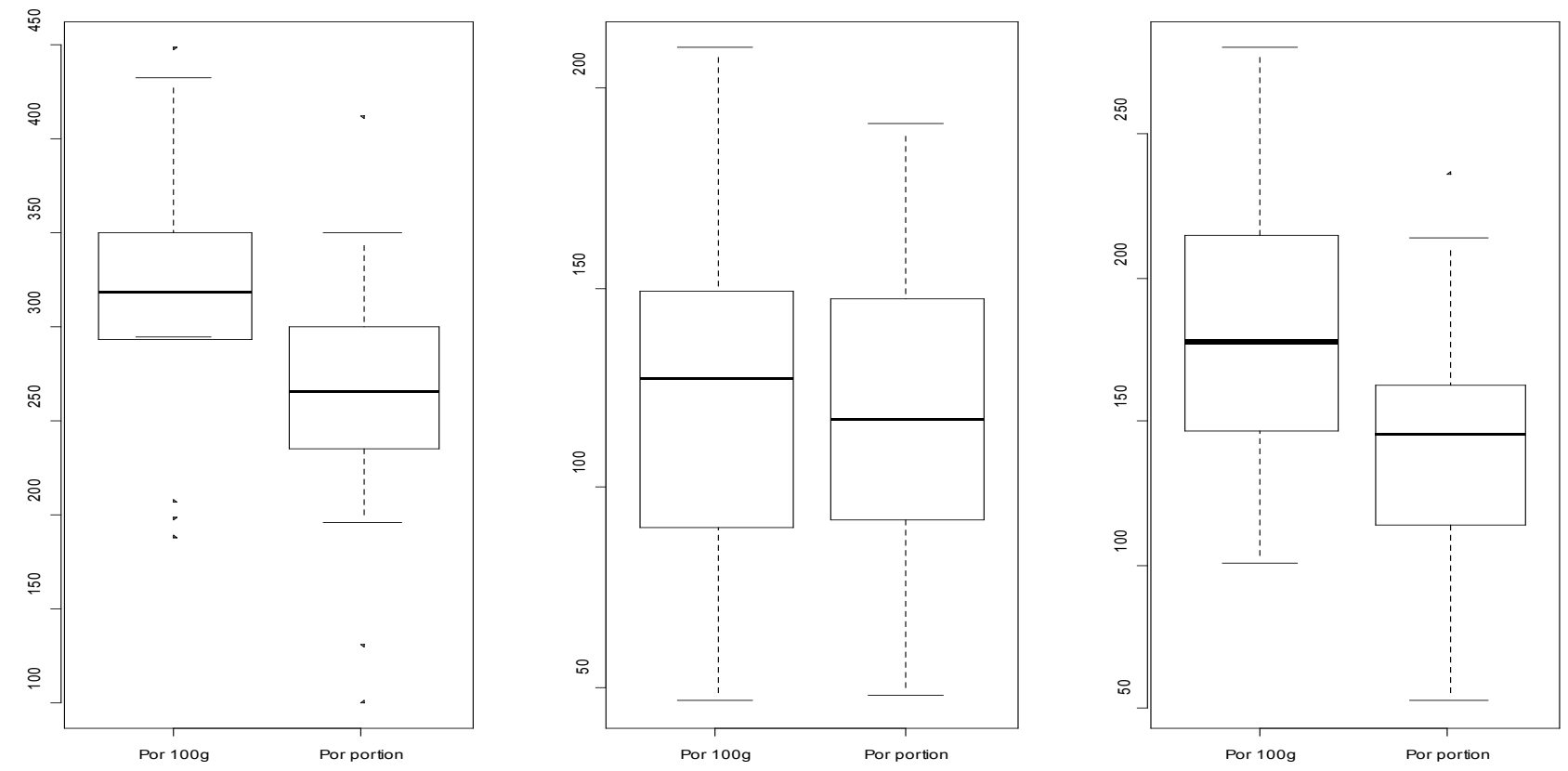

Fig. (2). Kcal related to participants who do not usually read Nutrition Information. The first box-plot is referred to both meals. The second and the third are respectively referred to kids' and adults' meal.

countries like the South Americans Mexico, Argentina, Brazil, Chile, Colombia, Ecuador, Paraguay and Uruguay.

The idea that labeling use and trust could benefit overall diet has been investigated in experimental settings, showing promising results [18]. However, when considering real-life scenarios, despite the mandatory regulation or the widespread use of nutrition facts labels, both in FOP and in back-of-package (BOP), nutrition literacy is lower than expected [19]. Grunert has identified lack of time, concerns about accuracy of the information as well as difficulty in understanding the information, among the prominent reasons why consumers fail to use the nutritional information in their actual food choice behavior [19]. Moreover, many consumers appeared to find information confusing, with subsequent inability to translate information into actual purchasing behavior [20].

The majority of consumers generally stated to understand nutrition labels well or in part, but it's otherwise recognized that actual understanding of label terms and concepts is poor across all types of nutrition information [3]. Consistent with these results, the present study showed that consumers were not habitually observing nutritional facts presented on labels, and that were more likely to remember the presence on labels of information like the expiry date of the site of production rather than on contents.

With regard to the regulatory apparatus on nutrition labels, the choices of reference amounts have been influenced by the local regulatory environment. In the EU, 
nutrition labeling is provided per $100 \mathrm{~g}$ while in the United States, such information is provided only for the portion defined by the Food and Drug Administration (FDA) as a reference amount customarily consumed (RACC) [7]. In Chile, a law called "Nutritional Composition of Nutrients and Their Advertising" which became official in July 2012, being the first in the world to require label warning statements on foods high in fat, sugar, and salt, reported Brussels-based regulatory consultant European Advisory Services (EAS) Europe in a June press release. This law established standards to allow clear and understandable information to consumers on the content of the products, in order to guide the decision-making process.

One of the potential puzzling factors has proven to be the definition of Kcal per measured amounts of food. These labels are intended to compare the nutritional information of different foods belonging to the same category. The Nutrition Information Panel (NIP) displays the content of energy, fat, saturated fat, protein, carbohydrate, sugar, and sodium per serving and per 100 grams of food [21]. The methods of measurement include: 100gr, cups and tablespoons for granular items; fractions for sliced items like pie or cake; numbers for grouped items like cherries or grapes; and grams for other grouped items, such as cereals.

In the present study, content of nutrients was expressed in relation to the energy $(100 \mathrm{kcal}$ of energy or macronutrient), given with reference to portion or $100 \mathrm{gr}$ of product. These assessments allowed easy comparisons with nutrition recommendations and guidelines, usually expressed per $2000 \mathrm{kcal}$ daily ratio [22]. When directly asked to state their preference on labeling format, consumers choose $\mathrm{Kcal} /$ per portion method, that was perceived as an easier tool both when considering purchasing and consuming.

In overall meal preparation, the participants prepared meals with higher energy intake when using products with indication given per 100 gr. This phenomenon was significant when considering those who weren't habitually reading labels. These results were in line with previous studies. The use of $100 \mathrm{~g}$ or $100 \mathrm{kcal}$ of food labels has its own advantages and disadvantages [23]. Expressing nutrient content on a per serving/portion basis was considered as the only approach directly related to the quantity of food typically consumed [23]. Although many food products are labeled in this way, yet there are no standardized serving/portion sizes for different groups of food products defined [24]. The choice of reference amounts may have a major impact on the eligibility of different foods or food groups for bearing health claims. An important factor in comprehension of food labels appeared to be the consumer's level of literacy and numeracy, with poor comprehension being highly correlated with literacy and numeracy low-level skills [25].

The study was important to understand whether people are able to use and understand labeling on foods. Similar to Wills results [8], consumers said they look at calorie information on the nutritional fact label, without correctly placing these information in the context of their total energy requirements. This consideration could be confirmed in the last session of the questionnaire, where participants were asked to pick the picture figuring the correct portion of a healthy diet. Correct answers were given in the totality of questions concerning the principal meals, with respondents in choosing the reduced portion the majority of cases, showing unclear ideas on which were the values of a balanced meal. An interesting finding was that when questioned on snacks, participants gave the correct answers in the large majority of cases. The ability to estimate portion sizes of foods remained a problem as seen in other studies $[26,27]$, in a sample that showed a general low knowledge and interest on food labeling. As seen in the practical phase, participants were more likely to correctly prepare a balanced portion when indications were given in an FOP label that described Kcal compared to portion size. Awareness should be enhanced [28], taken that at the time of the study, the sample showed a very low understanding and use of the labeling system.

Nielsen and Popkin added to the list of possible interventions by proposing that portion sizes should be controlled using pricing strategies, in order to prevent consumers drifting toward the purchase of financially more attractive large portions [24]. Furthermore, as reported by McIlveen, consumer attitudes are important factors in food product development, and point-of-purchase settings base many corporate decisions on them [29].

In conclusion, portion size use seemed to be more intuitive with respect to properly shared nutritional information, especially when considering common traditional recipes.

Meals responsible appeared to be much more at ease when using per portion labeling, when preparing both children's meals and adult ones.

\section{CONFLICT OF INTEREST}

The authors confirm that this article content has no conflicts of interest.

\section{ACKNOWLEDGEMENTS}

This research was partially funded by an unrestricted grant of the University of Padova and of Prochild ONLUS. The research did benefit also from a technical grant of ZETA Research Ltd for conducting the Survey. The work has been partially supported by an unrestricted grant of the Italian Ministry of Foreign Affairs under the program "Programmi di alta rilevanza scientifica e tecnologica Italia-Messico".

\section{REFERENCES}

[1] WHO World Health Organization. Global Strategy on Diet, Physical Activity and Health. World Health Organization 2004

[2] Conway MJ, Rhodes DG, Rumper WV. Commercial PortionControlled Foods in Research Studies: How Accurate Are Label Weights? J Am Diet Assoc 2004; 104: 1420-4.

[3] Van den Wijngaart AW. Nutrition labelling: purpose, scientific issues and challenges. Asia Pac J Clin Nutr 2002; 11(2): S68-71.

[4] Sung-Yong K, Nayga RM, Capps O. Food Label Use, SelfSelectivity, and Diet Quality. J Consumer Aff 2001; 35(2): 346-63.

[5] McLean-Meyinsse PE. An analysis of nutritional label use in the southern united states. J Food Distrib Res 2001; 32(01).

[6] Randell AW, Whitehead AJ. Codex Alimentarius: food quality and safety standards for international trade. Rev Sci Tech 1997; 16(2): 313-21.

[7] C. H. Nutrition Labels and Health Claims: the Global Regulatory Environment Geneva: World Health Organization 2004. 
[8] Wills JM, Schmidt DB, Pillo-Blocka F, et al. Exploring global consumer attitudes toward nutrition information on food labels. Nutr Rev 2009; 67: S102-S6.

[9] van Kleef E, van Trijp H, Paeps F, et al. Consumer preferences for front-of-pack calories labelling. Public Health Nutr 2008; 11(2): 203-13.

[10] McLean-Meyinsse PE. An analysis of nutritional label use in the Southern United States. J Food Distrib Res 2001; 32(1): 110-4.

[11] Kim S, Nayga RM, Capps O. Food label use, self-selectivity, and diet quality. J Consum Aff 2001; 35(2): 346-63.

[12] Kim S, Nayga RM, Capps O. The effect of food label use on nutrient intakes: an endogenous switching regression analysis. J Agric Resource Econ 2000; 24(1): 215-31.

[13] Cowburn G, Stockley L. Consumer understanding and use of nutrition labelling: a systematic review. Public Health Nutr 2005; 8(1): 21-8.

[14] FSA. Qualitative Signposting Labelling Refinement Research. In: FSA. Rcob Sf, Ed. London: FSA 2005.

[15] Ledikwe JH, Ello-Martin JA, Rolls BJ. Portion sizes and the obesity epidemic. J Nutr 2005; 135: 905-9.

[16] Verbeke W. Agriculture and the food industry in the information age. Eur Rev Agric Econ 2005; 32(3): 347-68.

[17] Feunekes GIJ, Gortemaker IA, Willems AA, et al. Front-of-pack nutrition labelling: Testing effectiveness of different nutrition labelling formats front-of-pack in four European countries. Appetite 2008; 50(1): 57-70.

[18] Kim S-Y, Nayga RM, Capps O. Food label use, self-selectivity, and diet quality. J Consum Aff 2001; 35(2): 346-63.

[19] Grunert KG, Fernandez-Celemin L, Wills JM, et al. Use and understanding of nutrition information on food labels in six European countries. Z Gesundh Wiss 2010; 18(3): 261-77.
[20] EUFIC, Ed Nutrition Information and Food Labelling. EUFIC Forum No. 2.; 2005; Brussels.

[21] Legault L, Brandt MB, McCabe N, et al. 2000-2001 food label and package survey: an update on prevalence of nutrition labeling and claims on processed, packaged foods. J Am Diet Assoc 2004; 104(6): 952-8.

[22] Harper AE. Nutritional requirements and dietary allowances. Compr Ther 1978; 4(10): 10-7.

[23] Drewnowski A, Maillot M, Darmon N. Should nutrient profiles be based on 100 g, $100 \mathrm{kcal}$ or serving size. Eur J Clin Nutr 2009; 63: 898-904.

[24] Nielsen SJ, Popkin BM. Patterns and trends in food portion sizes. JAMA 2003; 289: 450-3.

[25] Rothman RL, Housam R, Weiss H, et al. Patient understanding of food labels: the role of literacy and numeracy. Am J Prev Med 2006; 31(5): 391-8.

[26] Korkalo L, Erkkola M, Fidalgo L, et al. Food photographs in portion size estimation among adolescent Mozambican girls. Public Health Nutr 2012; 8: 1-7.

[27] Lee CD, Chae J, Schap TE, et al. Comparison of known food weights with image-based portion-size automated estimation and adolescents' self-reported portion size. J Diabetes Sci Technol 2012; 6(2): 428-34.

[28] Brindal E, Wilson C, Mohr P, et al. Perceptions of portion size and energy content: implications for strategies to affect behaviour change. Public Health Nutr 2012; 15(2): 246-53.

[29] McIlveen H. Product development and the consumer: the reality of managing creativity. Nutr Food Sci 1994; 6: 26-30.

Received: January 22, 2013

(C) Gregori et al.; Licensee Bentham Open.

This is an open access article licensed under the terms of the Creative Commons Attribution Non-Commercial License (http://creativecommons.org/licenses/by-nc/3.0/) which permits unrestricted, non-commercial use, distribution and reproduction in any medium, provided the work is properly cited. 